\title{
Clinical Features, Endoscopic Management and Outcome of Patients with Non-variceal Upper Digestive Bleeding by Dieulafoy Lesion
}

\section{Adrian Goldiş, Raluca Lupuşoru* and Daniela Lazar}

Department of Gastroenterology and Hepatology, University of Medicine and Pharmacy "Victor Babeş" Timişoara, Romania

"Corresponding author: Dr. Raluca Lupusoru, Department of Gastroenterology and Hepatology, University of Medicine and Pharmacy "Victor Babeş", Liviu Rebreanu Boulevard, no. 156, 300723 Timişoara, Romania, Tel: +4-0356-433121; E-mail: raluca_lupusoru@yahoo.ro

Received date: May 24, 2017; Accepted date: June 27, 2017; Published date: July 04, 2017

Copyright: (c) 2017 Goldiş A, et al. This is an open-access article distributed under the terms of the Creative Commons Attribution License, which permits unrestricted use, distribution, and reproduction in any medium, provided the original author and source are credited.

\begin{abstract}
:
Aim and background: Dieulafoy lesion (DL) represents a rare, but important cause of major upper digestive bleeding, especially in elders. The aim of the study consists in identifying the clinico-biological and endoscopic features and the outcome of these patients.

Methods: We retrospectively evaluated the patients admitted with non-variceal upper digestive bleeding (UDB) in the Department of Gastroenterology, of the Emergency County Hospital Timisoara, from 2003 to 2014. Out of the total number of cases we selected the patients with endoscopic diagnosis of Dieulafoy lesion. In these patients we analyzed the demographic, clinico-biological and endoscopic data, compared to the control group that encountered the rest of the patients with UDB.
\end{abstract}

Results: Out of 2104 patients with non-variceal UDB, 31/2104 (1.5\%) presented DL, 19/31(61.3\%) male and $12 / 31(38.7 \%)$ female, mean age $63 \pm 12.83$. Diabetes mellitus was present in $35.5 \%$ cases. The mean value of hemoglobin was significantly lower in Dieulafoy group $7 \pm 2.69$ vs. $8 \pm 3.28$ in the control group, $p=0.05$, thus a significantly larger number of blood units per patient were needed in this group $(p<0.0001)$. Re-bleebing was encountered significantly more often in Dieulafoy vs. control group: $7 / 31(22.6 \%)$ vs. $173 / 2074(8.34 \%), p=0.03$; surgery was needed in $3 / 31(9.7 \%)$ Dieulafoy patients. Endoscopic haemostasis was achieved most frequently by using combined treatment. The use of anticoagulants had a significant influence in the development of $\mathrm{DL}$ $(p=0.019)$.

Conclusion: DL may cause massive bleeding and is associated with a high rate of re-bleeding. Patients present comorbidities, diabetes mellitus being mostly associated with this condition. Anticoagulants represent risk factors highly associated with DL.

Keywords: Dieulafoy lesion; Non-variceal upper digestive bleeding; Endoscopic haemostasis

\section{Introduction}

Upper digestive bleeding (UDB) presents an incidence ranging from 48 to 160 cases per 100,000 adults per year, and a mortality of $10-14 \%$ [1], being one of the major emergency conditions in gastroenterology, therefore associated with a major economic and clinical impact Dieulafoy lesion (DL), although an uncommon cause of non-variceal UDB, may cause potentially life-threatening bleeding, especially in the elderly [2].

The pathogenesis of this condition is considered to be the presence of abnormal large-caliber arteries at the submucosal level, subsequently causing the thinning of the overlying mucosa, producing erosions and leading to exposure of the vessel wall to the lumen, finally with the possibility of developing digestive hemorrhage [3].

This lesion was first described by Gallard and later named for the French surgeon Georges Dieulafoy who called it "exulceratio simplex" believing that it was the first stage of a gastric ulcer, the progression of which being stopped by the occurrence of hemorrhage [4,5]. The majority of DL occur in the proximal stomach, typically located within
$6 \mathrm{~cm}$ of the gastroesophageal junction on the lesser curvature, due to arterial vessels directly branching from the left gastric artery [6-8], but they have also been reported in the esophagus, small and large bowel [9-11] and also other rare locations such as the rectum or the gallbladder [12-14].

The diagnosis of DL is usually made by endoscopy, the endoscopic diagnostic rate of the lesion being over $90 \%$ of the cases $[15,16]$. Often, diagnosis may be difficult especially during the initial episode of hemorrhage due both to the small size of the lesion and the intermittent nature of the bleeding therefore a lot of patients require multiple endoscopic examinations for accurate diagnosis [6,17]. The condition was initially treated surgically [18]; with the advance of endoscopic techniques, nowadays therapeutic endoscopy is the treatment of choice, the hemostasis success rates achieving $75-100 \%$ $[17,19-24]$.

The aim of our study is to identify the clinico-biological and endoscopic characteristics, as well as the outcome of the patients with Dieulafoy lesions, admitted with upper digestive bleeding in an emergency hospital, which is a referral center for the western part of Romania. 


\section{Methods}

\section{Patients}

This was a retrospective study of the patients who were admitted to Clinical Emergency County Hospital Timisoara, Romania with a diagnosis of non-variceal upper digestive bleeding (UDB) between January 2003 and December 2014. Out of the 2104 patients with UDB, we selected a group of 31 patients who were endoscopically diagnosed with Dieulafoy lesions (DL). The 2073 patients in the control group were selected from patients who were admitted during the same period with non-variceal UDB due to other causes than Dieulafoy lesions. Patient information was collected by reviewing medical records, which included information regarding demographic data, medication history (aspirin consumption, use of anticoagulants), hemodynamic status at admission, blood test results, endoscopic details such as description of the lesions, the methods of endoscopic hemostasis applied and their efficacy (rate of re-bleeding, death, or need for surgery), associated comorbidities and the number of hospitalization days. All data were compared between the Dieulafoy group and the control group.

All the patients with UDB received treatment with proton pump inhibitors (PPI) started at the time of admission, using high doses of PPI ( $80 \mathrm{mg}$ IV bolus, followed by $8 \mathrm{mg} / \mathrm{h}$ continuous perfusion for 72 hours) in all cases. All the endoscopic procedures were performed in emergency conditions within 12 hours after admission, after the hemodynamic stabilization of the patient, in the endoscopic unit of the gastroenterology department (that can function around the clock, if needed), by the specialist who was on duty. In all the cases, consent forms were signed by the patients or their relatives. For the accurate selection of the Dieulafoy lesion patient group, the medical and endoscopic records of these patients were reviewed in order to meet the diagnostic criteria of Dieulafoy lesions. Only patients who presented a definite endoscopic diagnosis of DL were included in the study group.

\section{Endoscopic definitions and treatment}

Endoscopic diagnoses of Dieulafoy lesions were made according to the following diagnostic criteria established in the literature:

(1) Active arterial/micropulsatile bleeding from minute $(<3 \mathrm{~mm})$ mucosal defects; (2) presence of a protruding vessel \pm active bleeding during endoscopy, within a minute mucosal defect on the background of normal surrounding mucosa; or (3) an adherent clot attached to a minute mucosal defect/apparently normal mucosa $[8,17,25,26]$.

The endoscopic therapeutic methods applied in the case of DL were epinephrine $(1: 10,000)$ injection, hemoclipping, bipolar coagulation, argon plasma coagulation, or a combination treatment.

Initial failure of endoscopic hemostasis was defined as subsequent active bleeding despite performing endoscopic treatment or onset of active digestive hemorrhage (hematemesis, melena, hematochezia), and presence of hemodynamic instability (systolic blood pressure (SBP) below $100 \mathrm{mmHg}$, heart rate over 100 per minute) within 12 hours of initial endoscopic treatment.

Re-bleeding was defined as the reappearance of active digestive bleeding (hematemesis, melena and hematochezia), or hemodynamic instability, or with the decrease of hemoglobin level of more than 2 $\mathrm{g} / \mathrm{dL}$ within 24 hours from the first endoscopy, with the endoscopic confirmation of active bleeding at the site of previously treated lesion.

\section{Statistical analysis}

The statistical analysis was performed using SPSS software, Version 20.0 (IBM SPSS Statistics) and Microsoft Office Excel 2007. The Kolmogorov-Smirnov test was used for testing the distribution of numerical variables. Mean value and standard deviation were calculated for numerical variables with normal distribution, while in cases of non-normal distribution, median values and range intervals were used. Qualitative variables were presented as numbers and percentages. Parametric tests (t-test) were used for the assessment of differences between numerical variables with normal distribution; and nonparametric tests (Mann-Whitney or Kruskal-Wallis tests) for variables with non-normal distribution. Multivariate analysis was performed using logistic regressions. Chi-square (X2) test (with Yates' correction for continuity) was used to compare proportions expressed as percentages ("n" designates the total number of patients included in a particular subgroup). 95\% confidence intervals were calculated for each predictive test and a $\mathrm{p}$-value $<0.05$ was considered as significant for each statistic test.

\section{Results}

Out of the total number of 2104 patients with non-variceal upper digestive bleeding, 31/2104 (1.5\%) have presented endoscopic bleeding from a Dieulafoy lesion. 19/31 (61.3\%) were male and 12/31 (38.7\%) female (Figure 1 ), mean age $63 \pm 12.83$ years (range $23-83$ years). The control group, including the rest of 2073 patients with UDB of other etiologies, consisted in 1257/2073 (60.6\%) male and 716/2073 (39.4\%) female (Figure 2), mean age $62 \pm 7.8$ years.

Applying the risk scores used to stratify UDB patients, we noticed that mean Rockall score in Dieulafoy group was significantly higher compared to the batch without Dieulafoy $(6 \pm 2.44$ vs. $5 \pm 1.77$, $\mathrm{p}=0.0019)$. Regarding the clinical status at admission, $7 / 31(22.6 \%)$ of the subjects presented hemodynamic shock. Mean value of hemoglobin was significantly lower in Dieulafoy group vs. control group $(7 \pm 2.69 \mathrm{~g} / \mathrm{dl}$ vs. $8 \pm 3.28 \mathrm{~g} / \mathrm{dl}, \mathrm{p}=0.05)$. Thus a significantly higher mean number of blood units per patient was needed in the group with DL vs. control group (2.5 units of blood/patient vs. 1.3 units of blood, $\mathrm{p}<0.0001$ ).

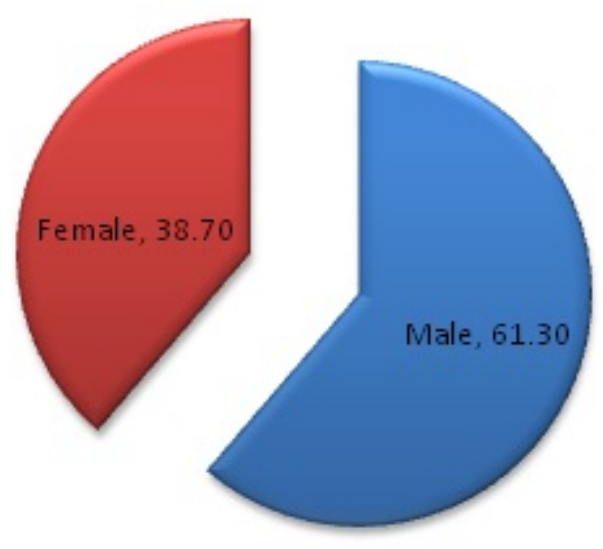

Figure 1: Dieulafoy group: gender distribution. 
Citation: Goldis A, Lupusoru R, Lazar D (2017) Clinical Features, Endoscopic Management and Outcome of Patients with Non-variceal Upper Digestive Bleeding by Dieulafoy Lesion. Biol Med (Aligarh) 9: 403. doi:10.4172/0974-8369.1000403

Page 3 of 6

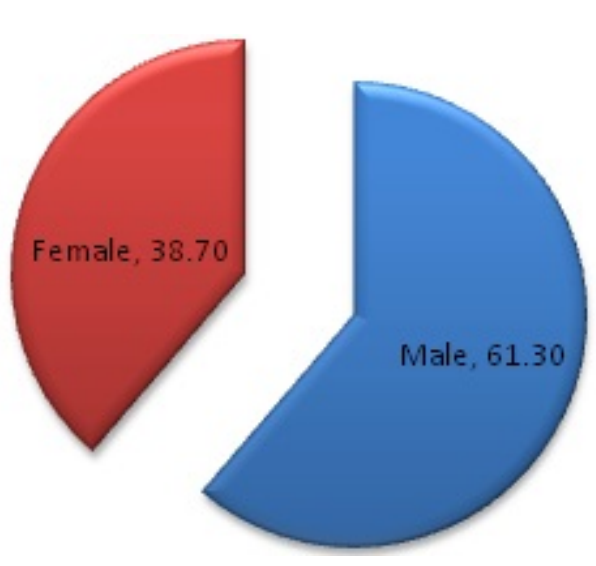

Figure 2: Control group: gender distribution.

Initial failure of endoscopic hemostasis was encountered in $2 / 24$ cases $(8.3 \%)$, that need surgical intervention, therefore we obtained an initial hemostatic success rate of $91.7 \%$

Re-bleeding was encountered significantly more often in the Dieulafoy group vs. the group without Dieulafoy: 7/31 (22.6\%) vs. $173 / 2073$ (8.34\%), $\mathrm{p}=0.03$. Re-bleeding was successfully treated using endoscopic methods of hemostasis, except one case that needed surgery.

The rate of transfer in surgery department due to failure of endoscopic hemostasis was: 3/31 (9.7\%) Dieulafoy patients vs. $79 / 2073$
(3.8\%), $\mathrm{p}=0.22$. The mean number of hospitalization days was greater for the Dieulafoy group 6.8 vs. 5.5 days, but without reaching statistical significance.

In more than one third-32.3\% of the Dieulafoy patients Aspirine consumption was encountered. The use of anticoagulants was significantly more frequently associated with the development of DL vs. control group: $8 / 31$ (25.8\%) vs. $226 / 2073$ (10.9\%), $\mathrm{p}=0.019$. In our study, there were no deaths encountered in the Dieulafoy group (Table $1)$.

Re-bleeding was encountered significantly more often in Dieulafoy group vs. the group without Dieulafoy: $7 / 31$ (22.6\%) vs. 173/2073 (8.34\%), $\mathrm{p}=0.03$. The need of surgery due to failure of endoscopic hemostasis was encountered in: 3/31 (9.7\%) Dieulafoy patients vs. $79 / 2073$ (3.8\%), $\mathrm{p}=0.22$. The mean number of hospitalization days was greater for the Dieulafoy group 6.8 vs. 5.5 days, but without reaching statistical significance.

Endoscopic haemostasis was achieved most frequently using epinephrine injection+hemoclipping $(\mathrm{EI}+\mathrm{HC})$ in $7 / 24$ patients (29.2\%), followed by epinephrine injection+bipolar coagulation (EI $+\mathrm{BC}$ ) in 5/24 patients (20.8\%), hemoclipping (HC) (16.7\%) and other therapies, such as the association of three methods- epinephrine injection+bipolar coagulation+hemoclipping in $2 / 24$ patients $(8.3 \%)$, or simple therapies like epinephrine injection and bipolar coagulation, each performed in $2 / 24$ patients $(8.3 \%)$. Other hemostatic methods encountered were represented by bipolar coagulation+hemoclipping and argon plasma coagulation (APC). In $7 / 31$ cases (22.6\%), there was no active bleeding during endoscopy, and therefore was no hemostatic procedure performed.

\begin{tabular}{|l|l|l|l|}
\hline \multirow{2}{*}{ Gender } & \multicolumn{1}{|c|}{ Dieulafoy group (n=31) } & \multicolumn{1}{|c|}{ Control group (n=2073) } & \multicolumn{1}{c|}{ P value } \\
\hline Mean age (years) & $19 / 31(61.3 \%)$ male & $1257 / 2073(60.6 \%)$ male & $p=0.98$ \\
\cline { 2 - 4 } & $12 / 31(38.7 \%)$ female & $716 / 2073(39.4 \%)$ female & $p=0.91$ \\
\hline Mean Rockall score & $63 \pm 12.83$ & $62 \pm 7.8$ & $p=0.48$ \\
\hline Hemodynamic shock & $6 \pm 2.44$ & $5 \pm 1.77$ & $\mathrm{p}=0.0019$ \\
\hline Mean value of hemoglobin (g/dl) & $7 / 31(22.6 \%)$ & $354 / 2073(17 \%)$ & $\mathrm{p}=0.56$ \\
\hline No. of blood units/patient & $7 \pm 2.69$ & $8 \pm 3.28$ & $\mathrm{p}=0.05$ \\
\hline Re-bleeding & $2.5 \pm 0.1$ & $1.3 \pm 0.1$ & $\mathrm{p}<0.0001$ \\
\hline Surgery & $7 / 31(22.6 \%)$ & $173 / 2073(8.34 \%)$ & $\mathrm{p}=0.03$ \\
\hline Mean number of hospitalization days & $3 / 31(9.7 \%)$ & $79 / 2073(3.8 \%)$ & $\mathrm{p}=0.22$ \\
\hline Aspirine consumption & $6.3 \pm 0.2$ & $5.5 \pm 0.12$ & $\mathrm{p}=0.49$ \\
\hline Anticoagulants & $32.3 \%$ & $21.8 \%$ & $\mathrm{p}=0.23$ \\
\hline Deaths & $8 / 31(25.8 \%)$ & $226 / 2073(10.9 \%)$ & $\mathrm{p}=0.019$ \\
\hline
\end{tabular}

Table 1: Comparison betmen demographic, clinico-biological characteristics and outcome of the patients included in Dieulafoy group vs. control group.

For the control group, endoscopic haemostasis was achieved most frequently using epinephrine injection+hemoclipping $(\mathrm{EI}+\mathrm{HC})$ in $726 / 2073$ patients (35\%), followed by epinephrine injection+bipolar coagulation (EI+BC) in 401/2073 patients (20\%), hemoclipping (HC) $(10 \%)$ and other therapies, such as the association of three methodsepinephrine injection+bipolar coagulation+hemoclipping in $30 \%$ 
patients, or simple therapies like epinephrine injection and bipolar coagulation, each performed in $5 \%$ patients. Other hemostatic methods encountered were represented by bipolar coagulation themoclipping and argon plasma coagulation (APC).

Regarding the presence of comorbidities, cardiovascular diseases, diabetes mellitus and renal diseases were encountered more frequently in Dieulafoy group vs. the control group: $77.4 \%$ vs. $60.4 \%, 35.5 \%$ vs. $18.9 \%$ and $29 \%$ vs. $18.5 \%$, but significant statistical differences were found only for the association of diabetes mellitus ( $\mathrm{p}=0.03$ ) (Table 2). Respiratory and neurological disorders were present each in $2 / 31$ patients (6.5\%); no patient was diagnosed with sepsis.

\begin{tabular}{|l|l|l|l|}
\hline \multicolumn{1}{|c|}{ Comorbidities } & $\begin{array}{c}\text { Dieulafoy group } \\
(\mathbf{n}=\mathbf{3 1})\end{array}$ & $\begin{array}{c}\text { Control group } \\
(\mathbf{n = 2 0 7 3 )}\end{array}$ & $\mathbf{P}$ value \\
\hline Cardiovascular diseases & $24 / 31(77.4 \%)$ & $1252 / 2073(60.4 \%)$ & $\mathrm{p}=0.08$ \\
\hline Diabetes mellitus & $11 / 31(35.5 \%)$ & $391 / 2073(18.9 \%)$ & $\mathrm{p}=0.03$ \\
\hline Renal diseases & $9 / 31(29 \%)$ & $333 / 2073(13.5 \%)$ & $\mathrm{p}=0.20$ \\
\hline Neoplasia & $4 / 31(13 \%)$ & $325 / 2073(15.7 \%)$ & $\mathrm{p}=0.87$ \\
\hline Cirrhosis & $2 / 31(6.5 \%)$ & $204 / 2073(9.9 \%)$ & $\mathrm{p}=0.75$ \\
\hline
\end{tabular}

Table 2: Comorbidities of the patients included in Dieulafoy group and control group.

\section{Discussion}

Dieulafoy's lesion, known to be a "caliber persistent artery" [27], is an uncommon, but potentially life-threatening, cause of digestive bleeding. It is difficult to determine its real incidence in the general population because they can cause intermittent bleeding and the endoscopic diagnosis is difficult, therefore it may be an underrecognized rather than a truly rare condition. DL may determine up to $6 \%$ of nonvariceal bleeding in the upper gastrointestinal tract $[28,29]$ and $1 \%$ to $2 \%$ of all acute digestive hemorrhage $[16,30]$.

In our hospital, the prevalence of non-variceal upper digestive bleeding due to DL was $1.5 \%$, percentage similar to the one found in other studies [26,31]. Although most of the researches have shown that Dieulafoy lesions are an uncommon cause of GI bleeding, the results of Lim and colab found them to be a relatively frequent etiology, accounting for $14.1 \%$ of nonvariceal upper gastrointestinal bleeding [20].

The demographic characteristics of our Dieulafoy patients were similar to those in other studies. We noticed a higher prevalence of the condition in men, compared to women, a gender characteristic that is valid for all the patients with non-variceal UDB, and an average age of 63 years.

Data from the literature show that DL usually affects elderly patients with associated comorbidity, such as cardiovascular disease, arterial hypertension, diabetes mellitus or renal failure, and also other conditions like respiratory disease, liver cirrhosis, neurological disease and use of medication that influence coagulation [31-33]. The proposed underlying mechanism consists in the alteration of these conditions of the normal process of angiogenesis, with the subsequent formation of aberrant vessels with a constant caliber that increase the incidence of Dieulafoy. However, authors like Ding and colab [34] described the presence of DL in younger patients, having relatively few comorbidities. Their explanations have taken into consideration the fact that the real incidence of DL in elderly patients may be underestimated because this type of patients are more reluctant to undertake emergency endoscopy and also because comorbidities in elderly patients may increase the risk of emergency endoscopy that may be avoided by the clinicians. In our study, most of the patients with comorbidities presented mainly cardiovascular disease (77.4\%), diabetes mellitus (35.5\%) and renal disease (29\%). Diabetes mellitus was encountered significantly more often in patients with Dieulafoy lesion compared to the control group.

Compared to the control group, the patients with DL from our study have presented with more severe UDB, translated into a significantly more severe anemia and a significantly higher number of blood units needed/patient. Furthermore, patients from DL group presented a significantly higher mean Rockall score vs. the control group that can be explained, at least partially, by the frequent association of comorbidities.

Some studies have proposed a causal relation of DL with the use of nonsteroidal anti-inflammatory drugs and aspirin, the evoked pathogenesis depending upon erosive gastritis and the subsequent necrosis of the vascular wall induced by these drugs that may determine the rupture of the submucosal vessels, but there is little evidence in the literature in this regard $[3,25]$. However, other studies were able to demonstrate only for antiplatelet agents a significant association with Dieulafoy lesions [8]. In our study, although a high proportion (32.3\%) of the Dieulafoy patients had Aspirine consumption, it didn't show to be a significant association, in contrast to the use of anticoagulants that proved to be significantly more frequently associated with the development of DL.

A previous study showed that chronic drinking damages gastric mucosa of animals, increasing the risk of Dieulafoy lesion formation [35]. Some studies report a moderately strong association of UDB from DL in patients with advanced liver disease/cirrhosis, particularly advanced alcoholic liver disease [36-38]. In contrast to these reports, our data showed no significant differences regarding the presence of cirrhosis in Dieulafoy group vs. the control group (6.5\% vs. 9.8\%).

The risk of re-bleeding from Dieulafoy's lesions is reported in the literature to be between 9-40\% [17] and proved to be higher using endoscopic monotherapy compared with combined endoscopic methods $[3,16]$. The endoscopic methods of haemostasis are the treatment of choice in case of re-bleeding [39]. In our study, the rebleeding rate was similar to previous reports (22.6\%), and was encountered significantly more often in Dieulafoy vs. other causes of non-variceal upper digestive bleeding.

The use of non-steroidal anti-inflammatory drugs (NSAIDs) or anticoagulants and the presence of active stages of the Forrest classification at endoscopy have been significantly associated with the risk of re-bleeding [20]. Jamanca-Poma et al. reported that, despite the high rate of comorbidities, no significant relationship was found between comorbidity and re-bleeding risk in Dieulafoy patients [40]. In the study of Park and colab, kidney disease and infection were significant predictors of re-bleeding in patients with DL, especially when the combination of infection and kidney disease was not properly controlled by medical treatment. The authors concluded that more effective endoscopic management associated with the control of underlying diseases are needed to better prevent re-bleeding in this type of patients [41].

Recent advances in endoscopic techniques have increased the diagnosis rate of Dieulafoy's lesions and have significantly decreased 
the mortality from $80 \%$ to $8.6 \%[3,26]$. Fortunately, none of our patients included in Dieulafoy group died.

Endoscopic treatment is highly successful in terms of achieving initial hemostasis, with hemostasis success rates usually exceeding $90 \%$ $[19,25,26,42,43]$. Also, in our study, the initial hemostatic success rate was of $91.7 \%$.

There is no consensus guideline on the best treatment of DL, treatment options depending on the site of the lesion and the available expertise. Endoscopic haemostatic procedures that can be applied to DL can be classified into three groups: thermal (bipolar coagulation, heat probe coagulation and argon plasma coagulation), regional injection (epinephrine injection and sclerotherapy) and mechanical (banding and hemoclipping) [25,32,42]. In our study, endoscopic haemostasis was achieved most frequently by using combined treatment, such as epinephrine injection+hemoclipping followed by epinephrine injection+bipolar coagulation and hemoclipping as simple therapy. Interestingly, none of the endoscopists have chosen band ligation as hemostatic method.

Other endoscopic treatments that can be performed when classical hemostatic methods fail to succeed include over-the-scope clip (OTSC) that has been developed for the closure of small defects of the digestive wall [44]. There are only few studies reporting the use of this device for management of DL [45-47], showing its efficacy, therefore it may become applied in routine endoscopic therapy.

Hemospray (Cook Medical, USA), a novel inorganic powder, has recently been approved in Canada for the management of nonvariceal upper digestive bleeding [48,49]. It achieves hemostasis by adhering to the bleeding site, which leads to mechanical tamponade and by promoting thrombus formation [50]. Results on safety and efficacy appear to be promising for various etiologies of digestive bleeding including Dieulafoy lesions [51,52].

EUS-guided treatment of the underlying vessel could be considered when the conventional methods of hemostasis fail. EUS may help detection of the aberrant vessel in the submucosa [53], may confirm ablation of a Dieulafoy's lesion after endoscopic treatment by confirming absence of blood flow [3] and help directing the therapy when needed [54]. However, EUS routine clinical usefulness in the DL detection is limited [55].

Each endoscopic technique has both advantages and disadvantages and varying success rates [25]. Combined endoscopic therapy proved to be superior to monotherapy, with permanent hemostasis achieved in $95 \%$ of cases [3].

Literature data suggest that endoscopic mechanical hemostatic methods including hemostatic clipping and band ligation are more effective in achieving hemostasis when compared to injection or thermal methods, leading to less damage to the surrounding tissue $[25,43,56,57]$, therefore mechanical therapy could be chosen as the first-line approach for the management of DL.

Endoscopic treatment is nowadays the first option for the management of this type of lesion, whereas surgery or selective arterial embolization is appropriate only for cases with massive bleeding or endoscopic therapy failure $[18,58]$.

Surgery is currently reserved for the $5 \%$ of cases that are refractive to endoscopic/angiographic methods of hemostasis and the techniques employed include local excision of the lesion or a wedge resection of the affected section of gut $[30,59]$. Laparoscopic surgery is nowadays an attractive option being minimally invasive to the patient. However, successful laparoscopic resection relies on accurate localization of the site of hemorrhage [60]. In our DL group, the need of surgery due to failure of endoscopic hemostasis was encountered in $3 / 31$ patients $(9.7 \%)$.

\section{Conclusion}

In conclusion, our study shows that, although seldom encountered, Dieulafoy lesions may frequently cause massive bleeding, they are associated with a high rate of re-bleeding and can be successfully treated using endoscopic methods of haemostasis in more than $90 \%$ of the cases. Usually, patients diagnosed with DL have many comorbidities, diabetes mellitus being significantly associated with this condition. Anticoagulants represent risk factors frequently associated with Dieulafoy lesion formation.

\section{References}

1. Barkun AN, Bardou M, Kuipers EJ, Sung J, Hunt RH, et al. (2010) International consensus recommendations on the management of patients with nonvariceal upper gastrointestinal bleeding. Ann Intern Med 152: 101-113.

2. Nagri S, Anand S, Arya Y ( 2007) Clinical presentation and endoscopic management of Dieulafoy's lesions in an urban community hospital. World J Gastroenterol 13: 4333-4335.

3. Lee YT, Walmsley RS, Leong RWL, Sung JJY (2003) Dieulafoy's lesion. Gastrointest Endosc 58: 236-243.

4. Dupont M, Dieulafoy G (1999) Historical dictionary of physicians in and out of medicine. Larousse-Bordas, Paris.

5. Karamanoua M, Fiskab A, Demetrioub T, Androutsos G (2011) GeorgesPaul Dieulafoy (1839-1911) and the first description of "exulceratio simplex". Ann Gastroenterol 24: 188-191.

6. al-Mishlab T, Amin AM, Ellul JP (1999) Dieulafoy's lesion: An obscure cause of GI bleeding. J R Coll Surg Edinb 44: 222-225

7. Anireddy D, Timberlake G, Seibert D (1993) Dieulafoy's lesion of the esophagus. Gastrointest Endosc 39: 604

8. Shin HJ, Ju JS, Kim KD, Kim SW, Kang SH, et al. (2015) Risk factors for dieulafoy lesions in the upper gastrointestinal tract. Clin Endosc 48: 228-233.

9. Romaozinho JM, Pontes JM, Lerias C, Ferreira M, Freitas D (2004) Dieulafoy's lesion: Management and long-term outcome. Endoscopy 36: 416-420.

10. Enns R (2001) Dieulafoy's lesions of the rectum: A rare cause of lower gastrointestinal bleeding. Can J Gastroenterol 15: 541-545.

11. Blecker D, Bansal M, Zimmerman RL, Fogt F, Lewis J, et al. (2001) Dieulafoy's lesion of the small bowel causing massive gastrointestinal bleeding: Two case reports and literature review. Am J Gastroenterol 96: 902-905.

12. Kim HH, Kim JH, Kim SE, Park SJ, Park MI, et al. (2012) Rectal dieulafoy lesion managed by hemostatic clips. J Clin Med Res 4: 439-41.

13. Vila JJ, Pérez-Miranda M, Basterra M, Gómez M, Fernández-Urién I, et al. (2014) Endoscopic ultrasound-guided therapy of a rectal Dieulafoy lesion. Endoscopy 46: E84-85.

14. Stanes A, Mackay S (2016) Dieulafoy lesion of the gallbladder presenting with bleeding and a pseudo-mirizzi syndrome: A case report and review of the literature. Int J Surg Case Rep 21: 12-15.

15. Lara LF, Sreenarasimhaiah J, Tang SJ, Afonso BB, Rockey DC (2010) Dieulafoy lesions of the GI tract: localization and therapeutic outcomes. Dig Dis Sci 55: 3436-344.

16. Marangoni G, Cresswell AB, Faraj W, Shaikh H, Bowles MJ (2009) An uncommon cause of life-threatening gastrointestinal bleeding: 2 synchronous Dieulafoy lesions. J Pediatr Surg 44: 441-443. 
17. Jeon HK, Kim GH (2015) Endoscopic management of Dieulafoy's lesion. Clin Endosc 48: 112-120.

18. Veldhuyzen van Zanten SJ, Bartelsman JF, Schipper ME, Tytgat GN (1986) Recurrent massive haematemesis from Dieulafoy vascular malformations: A review of 101 cases. Gut 27: 213-222.

19. Ahn DW, Lee SH, Park YS, Shin CM, Hwang JH, et al. (2012) Hemostatic efficacy and clinical outcome of endoscopic treatment of Dieulafoy's lesions: Comparison of endoscopic hemoclip placement and endoscopic band ligation. Gastrointest Endosc 75: 32-38.

20. Lim W, Kim TO, Park SB, Rhee HR, Park JH, et al. (2009) Endoscopic treatment of dieulafoy lesions and risk factors for rebleeding. Korean J Intern Med 24: 318-322.

21. Walmsley RS, Lee YT, Sung JJ (2005) Dieulafoy's lesion: A case series study. World J Gastroenterol 11: 3574-3577.

22. Ljubicic N (2006) Efficacy of endoscopic clipping and long-term followup of bleeding Dieulafoy's lesions in the upper gastrointestinal tract. Hepatogastroenterology 53: 224-227

23. Kasapidis P, Georgopoulos P, Delis V, Balatsos V, Konstantinidis A, et al. (2002) Endoscopic management and long-term follow-up of Dieulafoy's lesions in the upper GI tract. Gastrointest Endosc 55: 527-531

24. Park CH, Joo YE, Kim HS, Choi SK, Rew JS, et al. (2004) A prospective, randomized trial of endoscopic band ligation versus endoscopic hemoclip placement for bleeding gastric Dieulafoy's lesions. Endoscopy 36: 677-681.

25. Chung IK, Kim EJ, Lee MS, Kim HS, Park SH, et al. (2000) Bleeding Dieulafoy's lesions and the choice of endoscopic method: comparing the haemostatic efficacy of mechanical and injection methods. Gastrointest Endosc 52: 721-724

26. Baxter M, Aly EH (2010) Dieulafoy's lesion: Current trends in diagnosis and management. Ann R Coll Surg Engl 92: 548-554.

27. Morowitz M, Markowitz R, Kamath B, Allmen D (2004) Dieulafoy's lesion segmental dilatation of the small bowel: an uncommon cause of gastrointestinal bleeding. J Paediatr Surg 39: 1726-1728

28. Stark ME, Gostout CJ, Balm RK (1992) Clinical features and endoscopic management of Dieulafoy's disease. Gastrointest Endosc 38: 545-550

29. Strong RW (1984) Dieulafoy's disease: A distinct clinical entity. Aust N Z J Surg 54: 337-339.

30. Chaer R, Helton WS (2003) Dieulafoy's disease. Am Coll Surg 196: 290-296.

31. Ibáñez A, Castro E, Fernández E (2007) Clinical aspects and endoscopic management of gastrointestinal bleeding from Dieulafoy's lesion. Rev Esp Enferm Dig 99: 505-510.

32. Schmulewitz N, Baillie J (2001) Dieulafoy lesions: A review of 6 years of experience at a tertiary referral center. Am J Gastroenterol 96: 1688-1694.

33. Nikolaidis N, Zezos P, Giouleme O (2001) Endoscopic band ligation of Dieulafoy-like lesions in the upper gastrointestinal tract. Endoscopy 33: 754-760.

34. Ding YJ, Zhao L, Liu J, Luo HS (2010) Clinical and endoscopic analysis of gastric Dieulafoy's lesion. World J Gastroenterol 16: 631-635.

35. Lee EA, Kim JB, Kim BS (2000) Morphological effect of chronic alcohol drinking upon the gastric mucosa of rats. Korean J Anat 33: 519-527

36. Fockens P, Tytgat GN (1996) Dieulafoy's disease. Gastrointest Endosc Clin N Am 6: 739-752.

37. Akhras J, Patel P, Tobi M (2007) Dieulafoy's lesion-like bleeding: An underrecognized cause of upper gastrointestinal hemorrhage in patients with advanced liver disease. Dig Dis Sci 52: 722-726.

38. Nojkov B, Cappell MS (2016) Distinctive aspects of peptic ulcer disease, Dieulafoy's lesion, and Mallory-Weiss syndrome in patients with advanced alcoholic liver disease or cirrhosis. World J Gastroenterol 22: 446-466.

39. Pathan NF, El-Fanek H (2006) A 70-year-old man with episodes of upper gastrointestinal bleeding. Dieulafoy lesion/malformation. Arch Pathol Lab Med 130: e27-e29.
40. Jamanca-Poma Y, Velasco-Guardado A, Piñero-Pérez C (2012) Prognostic factors for recurrence of gastrointestinal bleeding due to Dieulafoy's lesion. World J Gastroenterol 18: 5734-5738.

41. Park SH, Lee DH, Park CH (2015) Predictors of rebleeding in upper gastrointestinal Dieulafoy lesions. Clin Endosc 48: 385-391.

42. Iacopini F, Petruzziello L, Marchese M (2007) Hemostasis of Dieulafoy's lesions by argon plasma coagulation (with video). Gastrointest Endosc 66: 20-26.

43. Mumtaz R, Shaukat M, Ramirez FC (2003) Outcomes of endoscopic treatment of gastroduodenal Dieulafoy's lesion with rubber band ligation and thermal/injection therapy. J Clin Gastroenterol 36: 310-314.

44. Kirschniak A, Kratt T, Stüker D, Braun A, Schurr MO, et al. (2007) A new endoscopic over-the-scope clip system for treatment of lesions and bleeding in the GI tract: First clinical experiences. Gastrointest Endosc 66: 162-167.

45. Skinner M, Gutierrez JP, Neumann H, Wilcox CM, Burski C, et al. (2014) Over-the-scope clip placement is effective rescue therapy for severe acute upper gastrointestinal bleeding. Endoscopy International Open 2: E37E40.

46. Gomez V, Kabir K, Baig KR, Lukens FJ, Woodward T (2013) Novel treatment of a gastric Dieulafoy lesion with an over-the-scope clip. Endoscopy 45: E71.

47. Mangiavillano B, Arena M, Morandi E, Viaggi P, Masci E (2012) Successful treatment with an over-the-scope clip of Dieulafoy's gastric lesion resistant to conventional endoscopic treatment. Endoscopy 44: E387.

48. Yau AHL, Ou G, Galorport C (2014) Safety and efficacy of Hemospray ${ }^{\circledR}$ in upper gastrointestinal bleeding. Can J Gastroenterol Hepatol 28: 72-761.

49. Giday SA (2011) Preliminary data on the nanopowder hemostatic agent TC-325 to control gastrointestinal bleeding. Gastroenterol Hepatol 7: 620-622.

50. Aslanian HR, Laine L (2013) Hemostatic powder spray for GI bleeding. Gastrointest Endosc 77: 508-510.

51. Smith LA, Stanley A, Morris J (2012) Hemospray for non-variceal upper gastrointestinal bleeding: Results of the SEAL dataset (survey to evaluate the application of hemospray in the luminal tract. Gut 62: A61-A62.

52. Holster IL, Kuipers EJ, Tjwa ET (2013) Hemospray in the treatment of upper gastrointestinal hemorrhage in patients on antithrombotic therapy. Endoscopy 45: 63-66.

53. Schilling D, Jüngling B, Adamek HE, Benz C, Riemann JF (1999) The endoscopic diagnosis and therapy as well as the long-term course of Dieulafoy ulcer hemorrhage. Dtsch Med Wochenschr 124: 419-423.

54. Levy MJ, Wong Kee, Song LM (2008) Endoscopic ultrasound (EUS)guided angiotherapy of refractory gastrointestinal bleeding. Am J Gastroenterol 103: 352-359.

55. Seicean A (2013) Endoscopic ultrasound in the diagnosis and treatment of upper digestive bleeding: A useful tool. J Gastrointestin Liver Dis 22: 465-469.

56. Park CH, Sohn YH, Lee WS (2003) The usefulness of endoscopic hemoclipping for bleeding Dieulafoy lesions. Endoscopy 35: 388-392.

57. Katsinelos P, Paroutoglou G, Mimidis K (2005) Endoscopic treatment and follow-up of gastrointestinal Dieulafoy's lesions. World J Gastroenterol 11: 6022-6026.

58. Loffroy RF, Abualsaud BA, Lin MD, Rao PP (2011) Recent advances in endovascular techniques for management of acute nonvariceal upper gastrointestinal bleeding. World J Gastrointest Surg 3: 89-100.

59. Prasad TR, Lim KW, Lim KT, Yap TL (2007) Bleeding jejunal Dieulafoy pseudopolyp: capsule endoscopic detection and laparoscopic-assisted resection. J Laparoendosc Adv Surg Tech 17: 509-512.

60. Eisenberg D, Bell R (2009) Intraoperative endoscopy: A requisite tool for laparoscopic resection of unusual gastrointestinal lesions-a case series. J Surg Res 155: 318-320. 